\title{
TTF-1 and Napsin a Double Staining in Diagnosing Lung Adenocarcinoma
}

\section{Momin T. Siddiqui*}

Department of Pathology, Emory University Hospital, Atlanta, Georgia, USA

\section{Introduction}

Pulmonary cancer is the most commonly diagnosed cancer worldwide, and is the leading cause of cancer mortality in men [1]. Lung cancer is divided into small cell cancer and Non-Small Cell Cancer (NSCLC). NSCLC accounts for $80 \%$ of all lung cancers and is comprised of Adenocarcinoma (ADC), Squamous Cell Carcinoma (SqCCA) and large cell carcinoma [2]. In addition, 60\% of NSCLCs present with locally advanced disease at the time of initial diagnosis [3]. Traditionally, the pathologic lung cancer differential diagnosis was between small cell carcinoma and NSCLC, as sub-typing NSCLC had not been shown to predict differences in patient outcomes. Recent advances in molecular biology have led to an increase in target-specific chemotherapeutic therapies that require the sub-categorization of NSCLCs. The International Association for the Study of Lung Cancer, the American Thoracic Society, and the European Respiratory Society has outlined a new classification of lung ADCs based on a multidisciplinary approach. They have outlined the importance of further classifying NSCLCs as either ADCs or SqCCAs, since ADCs should be tested for Epidermal Growth Factor Receptor (EGFR) and Anaplastic Lymphoma Kinase (ALK) fusion gene mutations, as targeted chemotherapeutic agents can be used with greater efficacy [4]. Lung ADCs are often associated with EGFR mutations, and can be effectively treated with tyrosine kinase inhibitors such as gefitinib $[5,6]$. In addition, ADC have been shown to have improved outcomes when compared to SqCCAs when treated with pemetrexed therapy, which inhibits specific enzymes in purine and pyrimidine synthesis. Finally, the distinction between ADC and SqCCA can avoid potentially hazardous outcomes, as life-threatening hemorrhages have been rarely reported when patients with SqCCAs are treated with bevacizumab, a vascular endothelial growth factor inhibitor [7]. If the classification of NSCLCs cannot be achieved with cytologic/histologic criteria alone, Immunohistochemistry (IHC) staining should be employed. Thyroid Transcription Factor 1 (TTF-1) and Napsin A are both stains that have been proven to stain a majority of lung ADCs. TTF-1 is a nuclear stain that has been reported in $87 \%$ lung ADCs and $2 \%$ of SqCCAs [8]. Napsin A is a cytoplasmic stain that is relatively specific for ADC of the lung and reportedly stains $80 \%$ of cases [9]. A combined TTF-1 and Napsin A double stain has also been shown to be useful in the diagnosis of ADC in cell blocks from fine needle aspirates (FNAs) [10].

\section{Discussion}

In 2004, the World Health Organization (WHO) first addressed cytology in its lung cancer classification system [11]. The differentiation of NSCLC into ADC and SqCCA can be difficult when only limited tissue is present. In a series of bronchial biopsies from known lung cancer patients, only $48 \%$ of cases were found to have identifiable tumor [12]. Cytomorphologic accuracy when diagnosing ADC and SqCCA is reportedly $80 \%$ and $87 \%$, respectively [13]. This differentiation is further confounded by ADCs adopting degenerative changes such as coagulative necrosis, lending a pseudo-keratinized appearance. Similarly, SqCCAs can develop vacuolar degeneration, mimicking features of $\mathrm{ADC}$ and leading to inaccurate diagnoses that directly impact patient care decisions.

It is in these difficult scenarios that IHC can be used to achieve a greater diagnostic sensitivity and specificity than cytomorphology alone. The use of IHC has clearly increased in this regard over time; in a recent study by Ocque et al. [14] before 2004, only 14\% of ADCs and $8 \%$ of SqCCAs were subjected to IHC to make the definitive diagnosis, as opposed to $86 \%$ and $89 \%$ after 2004 , respectively. While this increase in IHC usage has had little effect on the diagnostic accuracy of SqCCA, accuracy has increased significantly for ADC diagnoses, reflecting the difficulty in assessing heterogeneous and poorly differentiated cases based on cytomorphology alone [14].

Thyroid Transcription Factor-1 (TTF-1), a nuclear stain expressed in pulmonary alveolar lining cells and follicular cells of the thyroid, has long been shown to have diagnostic usefulness in assessing ADCs for lung origin [15]. TTF-1 reportedly stains 73\% of ADCs and none of the SqCCA specimens in one series [16]. Pertaining specifically to FNA specimens, Liu and Farhood [15] showed TTF-1 positivity in $86 \%$ (12/14) lung ADCs and only 8\% (1/12) SqCCAs. Additionally, TTF-1 has been shown to be highly specific for lung ADC. In a series by Hecht et al. [8] 89\% (42/47) pulmonary ADCs were positive for TTF-1, while weak positivity was identified only in 1 of 50 (2\%) of non-pulmonary carcinomas (a metastatic ovarian carcinoma).

Napsin A, a cytoplasmic marker identified in type II pneumocytes and alveolar macrophages, has been shown to be positive in $83 \%$ of lung ADCs while negative in all SqCCAs in one study [16]. In a study by Kim et al. [17] evaluating Napsin A and TTF-1 staining of pulmonary ADC, Napsin A had a positivity rate of $83 \%$ (44/53) compared to TTF- 1 with 57\% (30/53). In addition, all non-pulmonary ADCs were negative for Napsin A and TTF-1. As these studies show, TTF-1 and Napsin A are both sensitive and specific for pulmonary ADC. However, recently Napsin A has been reported expressed in renal cell carcinoma, especially the papillary and clear cell types [18].

Our group (Fatima et al. [10]) has previously evaluated the use of a TTF-1/ Napsin A double stain with Leica antibody, to increase the specificity for diagnosis of ADCs, using a cohort of 35 ADC and 24 SqCCA cell blocks. In this study, 74\% (26/35) of ADCs were positive for both TTF-1 and Napsin A, with 12\% (3/24) SqCCAs also staining

*Corresponding author: Momin T. Siddiqui, Department of Pathology, G179B Emory University Hospital, 1364 Clifton Road NE, Atlanta, GA 30322, USA, Tel: 404-712-4188; Fax: 404-712-0714; E-mail: mtsiddi@emory.edu

Received June 05, 2012; Accepted June 08, 2012; Published June 11, 2012

Citation: Siddiqui MT (2012) TTF-1 and Napsin a Double Staining in Diagnosing Lung Adenocarcinoma. J Cytol Histol 3:e103. doi:10.4172/2157-7099.1000e103

Copyright: (c) 2012 Siddiqui MT. This is an open-access article distributed under the terms of the Creative Commons Attribution License, which permits unrestricted use, distribution, and reproduction in any medium, provided the original author and source are credited. 
Citation: Siddiqui MT (2012) TTF-1 and Napsin a Double Staining in Diagnosing Lung Adenocarcinoma. J Cytol Histol 3:e103. doi:10.4172/21577099.1000e103

positive for both, giving a sensitivity and specificity of $74 \%$ and $88 \%$, respectively. Interestingly, when taking only the TTF-1 stain into account, 37\% (9/24) of SqCCAs stained positive, lending a TTF-1 only specificity of $63 \%$. The TTF-1 Monoclonal Antibody (MAB) used, SPT24, has been previously shown to exhibit positive staining in a high percentage of pulmonary NSCLCs of all subtypes, and is a likely cause of the decreased specificity seen in this study [19].

Aberrant TTF-1 staining has also been identified in colon cancer, and TTF-1-positivity in colon cancer metastases to the lung is a known diagnostic dilemma [20,21]. A small series by Penman et al. [20] identified focal TTF-1 nuclear staining in 4 of 7 (56\%) primary colon carcinomas also using the SPT24 monoclonal antibody. Another study by Comperat et al. [21] compared the TTF-1 staining patterns using both the SPT24 and 8G7G1/1 clones. They showed 4 of 90 (5\%) colorectal primary and 4 of $41(10 \%)$ of colorectal cancer lung metastases at least focally stained with TTF-1 using the SPT24 clone; no aberrant staining was identified using the $8 \mathrm{G} 7 \mathrm{G} 1 / 1$ clone. They went on to test each clone on 86 primary lung ADCs, and determined the SPT24 clone to have a higher sensitivity (84\%) versus 8G7G1/1 (65\%) [21]. This increased sensitivity of the Leica SPT24 clone may account for the false positive staining reported by us in SqCCAs.

In summary, TTF-1/Napsin A as a useful marker for ADC should be used in conjunction with squamous markers such as P63/Cytokeratin 5 as a double stain, and the panel of stains (positive and negative) will determine whether the tumor is ADC or SQCCA, especially in limited samples such as FNA cell blocks.

\section{References}

1. Brambilla E, Travis WD, Colby TV, Corrin B, Shimosato Y (2001) The new World Health Organization classification of lung tumours. Eur Respir J 18: 1059-1068.

2. Travis WD (2002) Pathology of lung cancer. Clin Chest Med 23: 65-81.

3. American Cancer Society: Cancer Facts \& Figures 2004. 2005

4. Travis WD, Brambilla E, Noguchi M, Nicholson AG, Geisinger KR, et al. (2011) International association for the study of lung cancer/american thoracic society/ european respiratory society international multidisciplinary classification of lung adenocarcinoma. J Thorac Oncol 6: 244-285.

5. Hirsch FR, Spreafico A, Novello S, Wood MD, Simms L, et al. (2008) The prognostic and predictive role of histology in advance non-small cell lung cancer: a literature review. J Thorac Oncol 3: 1468-1481.

6. Asami K, Koizumi T, Hirai K, Ameshima S, Tsukadaira A, et al. (2011) Gefitinib as first-line treatment in elderly epidermal growth factor receptor-mutated patients with advanced lung adenocarcinoma: results of a Nagano Lung Cancer Research Group study. Clin Lung Cancer 12: 387-392.
7. Reck M, Barlesi F, Crinò L, Henschke Cl, Isla D, et al. (2011) Predicting and managing the risk of pulmonary haemorrhage in patients with NSCLC treated with bevacizumab: a consensus report from a panel of experts. Ann Oncol 23 : 1111-1120.

8. Hecht JL, Pinkus JL, Weinstein LJ, Pinkus GS (2001) The value of thyroid transcription factor-1 in cytologic preparations as a marker for metastatic adenocarcinoma of lung origin. Am J Clin Pathol 116: 483-488.

9. Suzuki A, Shijubo N, Yamada G, Ichimiya S, Satoh M, et al. (2005) Napsin A is useful to distinguish primary lung adenocarcinoma from adenocarcinomas of other organs. Pathol Res Pract 201: 579-586.

10. Fatima N, Cohen C, Lawson D, Siddiqui MT (2011) TTF-1 and Napsin A double stain: a useful marker for diagnosing lung adenocarcinoma on fine-needle aspiration cell blocks. Cancer Cytopathol 119: 127-133.

11. Travis WD, Rekhtman N, Riley GJ, Geisinger KR, Asamura H, et al. (2010) Pathologic diagnosis of advanced lung cancer based on small biopsies and cytology: a paradigm shift. J Thorac Oncol 5: 411-414.

12. Coghlin CL, Smith LJ, Bakar S, Stewart KN, Devereux GS, et al. (2010) Quantitative analysis of tumor in bronchial biopsy specimens. J Thorac Oncol 5: $448-452$.

13. Edwards SL, Roberts C, McKean ME, Cockburn JS, Jeffrey RR, et al. (2000) Preoperative histological classification of primary lung cancer: accuracy of diagnosis and use of the non-small cell category. J Clin Pathol 53: 537-540.

14. Ocque R, Tochigi N, Ohori NP, Dacic S (2011) Usefullness of immunohistochemical and histochemical studies in the classification of lung adenocarcinoma and squamous cell carcinoma in cytologic specimens. Am J Clin Pathol 136: 81-87

15. Liu J, Farhood A (2004) Immunostaining for thyroid transcription factor-1 on fine needle aspiration specimens of lung tumors. Cancer Cytopathol 102: 109-114.

16. Bishop JA, Sharma R, Illei PB (2010) Napsin A and thyroid transcription factor-1 expression in carcinomas of the lung, breast, pancreas, colon, kidney, thyroid and malignant mesothelioma. Hum Pathol 41: 20-25.

17. Kim JH, Kim YS, Choi YD, Lee JS, Park CS (2011) Utility of napsin A and thyroid transcription factor 1 in differentiating metastatic pulmonary from nonpulmonary adenocarcinoma in pleural effusion. Acta Cytol 55: 266-270.

18. Ordonez NG (2012) Napsin A expression in lung and kidney neoplasia: a review and update. Adv Anat Pathol 19: 66-73.

19. Matoso A, Singh K, Jacob R, Greaves WO, Tavares R, et al. (2010) Comparison of thyroid transcription factor- 1 expression by 2 monoclonal antibodies in pulmonary and nonpulmonary primary tumors. Appl Immunohistochem Mol Morphol 18: 142-149.

20. Penman D, Downie I, Roberts F (2006) Positive immunostaining for thyroid transcription factor- 1 in primary and metastatic colonic adenocarcinoma: a note of caution. J Clin Pathol 59: 663-664.

21. Compérat E, Zhang F, Perrotin C, Molina T, Magdeleinat P, et al. (2005) Variable sensitivity and specificity of TTF-1 antibodies in lung metastatic adenocarcinoma of colorectal origin. Mod Pathol 18: 1371-1376. 